\title{
Characterization of Fresh Oil Hydro Treating Catalysts
}

\author{
Jamal M.Amous \\ Chemical Engineering Department, College of Engineering, University of Hail, Saudi Arabia
}

Copyright $(2016$ by authors, all rights reserved. Authors agree that this article remains permanently open access under the terms of the Creative Commons Attribution License 4.0 International License

\begin{abstract}
Catalysts are of great importance in catalytic processes. Key features of oil hydrotreating catalysts are highlighted. These catalysts play a significant role in removing impurities, as sulfur and other hetero-atoms existing in these oil fractions. These catalysts are composed of mainly, molybdenum salts spread in the porous structure of the carrier, mainly $\gamma$-Alumina $\left(\gamma-\mathrm{Al}_{2} \mathrm{O}_{3}\right)$. Other metal salts supporting the action of the catalytic activity of Molybdenum, as Cobalt, Nickel, are added. The first step in the process of catalyst production is the drying of the wet salts mixture to remove moisture. The oxidic precursor is produced by the calcination of the dried mixture. The choice of the appropriate catalyst is based on its ability to maintain a high level of activity for long periods before re-activation. This ability depends on the chemical composition and on the porous structure of the carrier, which ensures the appropriate properties such as the density of active centers, particle strength, and porous structure parameters. Also, the catalyst resistance to chemical poisons destroying active centers in particular, is considered as a limiting factor in selecting the catalyst.
\end{abstract}

Keywords Co-Mo Catalysts, Hydro treatment, Porous structure, Promoter, Surface Chemistry, Activity

\section{Introduction}

The hydrotreatment of oil fractions is accomplished by the catalytic reaction of hydrogen with hetero-atoms present in petroleum fractions. Sulfur is the main harmful hetero atom present in these fractions. Other heteroatoms present are $\mathrm{N}$, $\mathrm{O}, \mathrm{Ni}, \mathrm{V}$. These atoms are removed by the catalytic hydrotreatment producing compounds of these hetero atoms bonded with hydrogen. For this purpose, huge amounts of catalysts are consumed annually in the widespread hydrotreatment units all over the world [1]. Hydrotreatment for refined products is accomplished efficiently under high temperature and pressure in the presence of hydrogen and a suitable catalyst having enhanced and controlled cracking activity [2].

From a commercial point of view it is necessary to consider the compositions of the cobalt -molybdenum and nickel- molybdenum carried on $\gamma$-Alumina support. The
Ni-Mo combination became increasingly important in situations where hydrogenation is desired. The nature of the chemical compounds present on the specific surface of the catalyst, determine both the selectivity and activity mode of the catalyst itself. Occelli and Rennard [3] showed that a supported Ni-Mo catalyst is active for hydrogenation-hydrocracking of vacuum gas oil feed stocks. In previous works, Merida et.al [4] described the method of preparation and the surface properties of fluorinated aluminaa-zirconium phosphate materials, as well as their use as supports for preparing Ni-Mo catalysts. These catalysts proved to be highly active for the hydrogenation reactions $[5]$.

Investigating the hydrotreating catalysts, M. de Jong et al., performed surface XPS analysis on catalyst samples made by impregnating thin films of Silica $\left(\mathrm{SiO}_{2}\right)$ and $\gamma$-Alumina carriers, with complexes of Cobalt and Molybdenum, found out that, $\mathrm{MoS}_{2}$ formation precedes the formation of cobalt sulfides at specified temperatures and that the performance of the tested catalysts is as those for catalysts with similar high specific surface areas [6].

Chemical properties depend on the active material's nature, concentration and dispersion on the carrier. The Molybdenum (Mo) sulfide acting as the catalyst and cobalt (Co) acting as promoter and stabilizer for the catalytic activity of Mo sulfide catalyst [7]. The preparation procedure and the conditions applied during the calcination have an important role on the determination of the final porous structure and on the nature of the different chemical species present. These processes have a direct and significant impact on the behavior of the final catalyst. The reduction and presulfidation processes are not less important than the calcination process. Reduction and presulfidation operations are usually carried in situ.

\section{Chemical Composition of Hydro-treating Catalysts}

Oil hydrotreating catalysts contain 2.5 to $5.0 \mathrm{wt} \%$ of the promoter which is usually Cobalt or Nickel oxides, while the mass ratio of the basic constituent, the Molybdenum oxide, is in the range between 10 to $15 \%$. It must be mentioned that Tungsten can replace Molybdenum, but the high cost of Tungsten is the main factor that prevents the wide 
application of Tungsten in these catalysts.

The mass fraction of the carrier which is usually $\gamma-\mathrm{Al}_{2} \mathrm{O}_{3}$ is in the range between $80-86.5 \mathrm{wt} \%$. Ahuja et al. [8] concluded that chemical composition of the catalyst affects strongly the chemical activity during the hydro desulfurization of Thiophene dissolved in Toluene. Also, they observed the dual Mo-Ni is effective in the cases were hydrogenation is desired and that the most suitable duals for hydro-desulfurization is that containing $\mathrm{Mo}$ and $\mathrm{Co}$ compounds.

Thermodynamic phase equilibrium curves support that under the applied operating conditions in Hydrodesulfurization (HDS) processes, the $\mathrm{MoS}_{2}$ and $\mathrm{Co}_{9} \mathrm{~S}_{8}$ are the most stable constituents, where little amounts of Hydrogen Sulfide are sufficient to convert all the Mo and Co oxides to the corresponding sulfides.

Richardson [9] studied the magnetic properties of various catalysts with cobalt and molybdenum compounds and concluded that unsulfided catalysts can be considered as mixtures of $\mathrm{Al}_{2} \mathrm{O}_{3}, \mathrm{CoAl}_{2} \mathrm{O}_{4}, \mathrm{CoO}, \mathrm{MoO}_{3}, \mathrm{CoMoO}_{4}$, and a "complex Co-Mo oxide". The active components of this mixture are those in which cobalt exists in an octahedral arrangement of oxide ions, e.g., $\mathrm{CoO}, \mathrm{CoMoO}_{4}$ and the Co-Mo complex. Tetrahedral cobalt, as in $\mathrm{CoAl}_{2} \mathrm{O}_{4}$, is presumed inactive. Ashley and Mitchell [10] concluded that Co-Mo catalysts contain cobalt (II) in about equal amounts of tetrahedral and octahedral configurations. Ashley and Mitchell detected no evidence of the existence of well-defined compounds in the catalyst. Richardson[9] and Ashley and Mitchell [10] reconciled between these two views, first by considering the catalyst as a mixture of compounds in a formal sense, second, in the hierarchy of activity of octahedral Co., Richardson [9] considered the $\mathrm{CoO}$ and $\mathrm{CoMoO}_{4}$ to be only moderately active, while the unspecified Co-Mo complex is stated to be the true catalyst. The fraction of this active complex was determined by magnetic measurements [11].

The chemical constituents of HDS catalysts were determined by Richardson [9] referring to their drying and calcination procedures. Richardson found out that at lower calcination temperatures, the $\mathrm{Co}$ forms are $\mathrm{CoO}$ and $\mathrm{CoAl}_{2} \mathrm{O}_{4}$. As the temperature of heat treatment increases, the concentration of tetrahedral $\mathrm{CoAl}_{2} \mathrm{O}_{4}$ increases at the expense of $\mathrm{CoO}$, and the magnetic moment falls. At about $650^{\circ} \mathrm{C}, \mathrm{CoMoO}_{4}$ begins to be formed competing favorably with $\mathrm{CoAl}_{2} \mathrm{O}_{4}$, and the magnetic moment increases again. Similar variations in the magnetic behavior of cobalt-alumina preparations were noted by Ashley and Mitchell [10] and by Greenwald [12] at somewhat higher temperatures. Greenwald [12] found his cobalt-alumina preparations, treated at $1500^{\circ} \mathrm{C}$, to be mixtures of tetrahedral and octahedral Co, while Ashley and Mitchell [10], who had calcined their cobalt aluminate at $1000^{\circ} \mathrm{C}$, deduced from magnetic measurements that the calcined cobalt aluminate is $100 \%$ tetrahedral cobalt. Richardson found that the concentration of active Co and Mo compounds is dependent on the initial Co-Mo ratio, as well as on the calcination-treatment temperatures.

The partial discrepancies between the results of the experimental surface investigations and theoretical thermodynamic data of the hydrotreating catalysts may be attributed to the probability that part of the Cobalt is bonded permanently to the surface of the carrier making the sulfidation of the cobalt atoms more difficult. Also, conducting the processes of reduction under unfavorable conditions may lead to the formation of Co-Mo compounds which are difficult to convert to sulfides. It must be mentioned also, that the high sensitivity of the sulfides to air Oxygen, may convert sulfides into the corresponding Co-Mo oxides upon taking the catalyst out of the reactor for surface analysis and examination.

Thus, the difficulty in obtaining reliable results concerning the chemical composition of the active phase of the catalyst led the researchers to refer back to basics supporting that the Molybdenum and Cobalt sulfides are the most stable compounds and these sulfides are the heart of the active phase of the catalyst. This conclusion is supported by the observed full similarity between the action of promoted catalyst carried on a porous carrier $\left(\gamma-\mathrm{Al}_{2} \mathrm{O}_{3}\right)$ and the unsupported catalysts $\mathrm{MoS}_{2}$ and $\mathrm{Co}_{9} \mathrm{~S}_{8}$.

\section{Catalyst Preparation and Generation of the Catalytic Activity}

A solution of Ammonium Paramolybdate salt is used to impregnate the $\gamma$-Alumina with the Molybdenum salt. The mixture is subjected to a drying process, and then the Cobalt Nitrate solution is added to impregnate the mixture with the Cobalt salt. Calcinations at moderate $\left(650-800{ }^{\circ} \mathrm{C}\right)$ temperatures process is then necessary to convert the solid mixture to the oxidic precursor of the catalyst.

The oxidic precursor is placed in the reactor for the reduction process which is to be carried under certain conditions of partial hydrogen pressure, $\mathrm{H}_{2}$ flow rate and temperature. Then the reduced catalyst is sulfided in situ by the hydrogen sulfide or the organic sulfur compound or carbon sulfide [13].

HamidA. Al-Mergen testing different HDS catalysts prepared by different methods arrived to the conclusion that applying the organic matrix combustion (OMXC) methods lead to catalysts which are more active up to approximately $60 \%$ as compared with the corresponding catalysts prepared by mechanical and conventional impregnation methods [14].

Usually, chemical materials are added to the catalyst, such as citric acid, silicon, sodium, boron and fluorine, to the impregnated carrier with Molybdenum and Cobalt for improving the performance of the catalyst [15-17]. Ammus [18] studied the deactivation phenomena associated with the application of $\mathrm{Co}-\mathrm{Mo} / \gamma-\mathrm{Al}_{2} \mathrm{O}_{3}$ catalysts and concluded that catalyst deactivation depends upon the porous structure parameters and the rate of coke and metals deposition on the catalyst particles. Deactivation due to Coke deposition is reversible and can be recovered, while metals deposition causes irreversible loss in catalyst activity [19]. 
Table 1. Physical and chemical features of $\mathrm{CoO}-\mathrm{MoO}_{3}$ catalysts with different supports [20]

\begin{tabular}{|c|c|c|c|c|c|c|}
\hline \multirow{2}{*}{ No. } & \multirow{2}{*}{ support } & \multicolumn{2}{|c|}{ Composition ${ }^{*} \mathrm{Wt} \%$} & \multirow{2}{*}{ color } & \multirow{2}{*}{$\begin{array}{l}\text { Surface area } \\
\mathrm{m}^{2} / \mathrm{g}\end{array}$} & \multirow{2}{*}{$\begin{array}{l}\text { Atomic ratio } \\
\mathrm{S}_{\text {total }} / \mathrm{Mo}^{* *}\end{array}$} \\
\hline & & $\mathrm{MoO} 3$ & $\mathrm{CoO}$ & & & \\
\hline 1 & $\gamma-\mathrm{Al}_{2} \mathrm{O}_{3}$ & 4 & - & white & 160 & $1.41^{* * *}$ \\
\hline 2 & $\gamma-\mathrm{Al}_{2} \mathrm{O}_{3}$ & 8 & - & white & 159 & 1.81 \\
\hline 3 & $\gamma-\mathrm{Al}_{2} \mathrm{O}_{3}$ & 12 & - & white & 152 & 2.00 \\
\hline 4 & $\gamma-\mathrm{Al}_{2} \mathrm{O}_{3}$ & 6 & 4 & gray & 150 & - \\
\hline 5 & $\gamma-\mathrm{Al}_{2} \mathrm{O}_{3}$ & 8 & 4 & Blue gray & 147 & - \\
\hline 6 & $\gamma-\mathrm{Al}_{2} \mathrm{O}_{3}$ & 12 & 4 & blue & 144 & 2.38 \\
\hline 7 & $\mathrm{SiO}_{2}$ & 4 & - & Pale yellow & 272 & 1.82 \\
\hline 8 & $\mathrm{SiO}_{2}$ & 8 & - & Pale Yellow green & 247 & 1.95 \\
\hline 9 & $\mathrm{SiO}_{2}$ & 12 & 4 & Violet gray & 223 & 2.4 \\
\hline 10 & $\mathrm{SiO}_{2}$ & 12 & 6 & Dark gray & 217 & 2.61 \\
\hline
\end{tabular}

: balance is $\gamma-\mathrm{Al}_{2} \mathrm{O}_{3}$

**:analyzed after sulfidation : $50 \mathrm{~cm}^{3} / \mathrm{min}$,

(NTP $\mathrm{H}_{2} \mathrm{~S} / \mathrm{H}_{2}$ ), volume ratio $1 / 6,400{ }^{\circ} \mathrm{C}$,

duration $2 \mathrm{~h}$.

$* * *: \mathrm{MoO}_{3} / \gamma-\mathrm{Al}_{2} \mathrm{O}_{3}$ : samples used for

analysis were supported on ketjen fluid powder

$\gamma-\mathrm{Al}_{2} \mathrm{O}_{3}$ grade $\mathrm{B}$.

Typical physical and chemical features of some oil hydrotrearting catalysts are shown in Table 1.

In Table 2, L. Coulier et.al, [21, 22], found out that HDS catalytic activity of promoted catalysts are higher than that for un promoted catalysts, while the hydrogenation selectivity is lower for the promoted catalysts compared with that for the un promoted samples. Also they observed that for supported and unpromoted catalysts, activity increases in the direction $\mathrm{SiO}_{2}<\mathrm{Al}_{2} \mathrm{O}_{3}<\mathrm{TiO}_{2}$.

Table 2. Thiophene HDS activity (\%) and (HYD) selectivity of $\mathrm{Al}_{2} \mathrm{O}_{3}$ supported catalysts

\begin{tabular}{|l|c|c|}
\hline Catalyst & $\begin{array}{c}\mathrm{HDS} \\
\text { activity\% }\end{array}$ & HYD(Butne/products) \\
\hline $\mathrm{Mo} / \mathrm{Al}_{2} \mathrm{O}_{3}$ & 0.37 & 0.04 \\
\hline $\mathrm{CoMo} / \mathrm{Al}_{2} \mathrm{O}_{3}$ & 0.72 & 0.01 \\
\hline $\mathrm{NiMo} / \mathrm{Al}_{2} \mathrm{O}_{3}$ & 2.84 & 0.02 \\
\hline
\end{tabular}

In Table 3, De Beer et.al, [23] testing promoted and un promoted $\mathrm{Mo} / \mathrm{Al}_{2} \mathrm{O}_{3}$ catalysts on thiophene hydro-desulfurization found out that catalytic activity increases, by increasing the $\mathrm{MoO}_{3}$ percentage and that promoted Mo catalysts showed higher activities than the un promoted catalysts.

Table 3. Effect of promoter and $\mathrm{MoO} 3 \mathrm{wt} \%$ on catalyst activity in thiophene dsulfurization

\begin{tabular}{|c|c|c|c|c|}
\hline $\mathrm{MoO}_{3}, \mathrm{wt} \%$, & 4 & 6 & 10 & 12 \\
\hline Conversion \%, $\mathrm{MoO}_{3} / \mathrm{Al}_{2} \mathrm{O}_{3} *$ & 3.8 & 8 & 21 & 23 \\
\hline $\begin{array}{c}\text { Conversion \%, } \\
\mathrm{CoO}-\mathrm{MoO}_{3} / \mathrm{Al}_{2} \mathrm{O}_{3} *\end{array}$ & 4.2 & 13.9 & 23 & 28 \\
\hline
\end{tabular}

*: $180 \mathrm{mg}$ catalyst, pre-reduced at $400^{\circ} \mathrm{C}, 50 \mathrm{~cm} 3 / \mathrm{min}, \mathrm{NTP}_{2}$ with 6 vol $\%$ Thiophene, run duration $1.5 \mathrm{~h}$ at $400^{\circ} \mathrm{C}$.

\section{Conclusions}

Oil hydrotreating catalysts play important role in the chemical industry of oil fractions hydrotreatment. Fractions contain impurities as sulfur, hetero-atoms, metals, the removal of these impurities is essential. These catalysts must have specifications that ensure catalysts long life, high activity and maintaining their activity for long periods. Pore size distribution, pore mean diameter, pore void fraction, specific surface area, particle mechanical strength, chemistry of pore walls with the active centers and dispersed chemical compounds are the main parameters affecting catalysts performance. Unsupported catalysts $\mathrm{MoO}_{3}$ show activities strongly dependent on the calcination temperature. Its activity drops as the calcinations temperature increases. Supported catalysts showed activities at higher levels depending on their high specific surface area. The promoting effect of cobalt can be clearly seen from the high Sulfur/molybdenum contents and from the higher desulfurization reaction rates accompanying the action of the promoted and supported Molybdenum catalysts against the unsupported catalysts.

\section{Acknowledgements}

Dr. Nader Okasha is gratefully thanked for his assistance in proofreading in this article.

\section{REFERENCES}

[1] B. Andrews, Cobalt-Molybdenum desulfurization Catalysts, 
chemistry and industry, 1396, 1960.

[2] M. S. Rana, V. Samano, Jorge Ancheyta, J. A. I. Diaze, “A review of recent advances on process technologies for upgrading of heavy oils and residua". Fuel, 86, 1216-1231, 2007.

[3] L.M. Occelli, R.J. Rennard, Hydrotreating catalysts containing pillared clays, Catal. Today, vol. 2, No.2-3, pp.309-319, 1988.

[4] J. Merida-Robles, P. Olivera-Pastor, A. Jimenez-Lopez, E. Rodriguez-Castellon, Preparation and Properties of Fluorinated Alumina-Pillared $\alpha$-Zirconium Phosphate Materials, J. Phys. Chem. 100 ,35, 14726, 1966.

[5] J. Merida-Robles, P. Olivera-Pastor, E. Rodrıguez-Castellon, A. Jimenez-Lopez, Fluorinated Alumina Pillared $\alpha$-Zirconium Phosphates as Supports for Metallic Nickel Catalysts, J. Catal. 169, 317.1997.

[6] M.de Jong et al., Surface Science Model of a Working Cobalt-Promoted Molybdenum Sulfide Hydrodesulfurization Catalyst: Characterization and Reactivity, J. Phys. Chem., 100, 17722-17724, 1996.

[7] Gian Paolo Chiusoli and Peter M. Maitlis, Metal-Catalysis in Industrial Organic Processes. Angewandte Chemie International Edition, Volume 46, Issue 21, pages 3791-3792, 2007.

[8] S. P. Ahuja, L. M. Derrien, and J. F. Le Page, Activity and selectivity of hydrotreating catalysts, Ind. Eng. Chem. Prod. Res. Develop. 9, 272, 1970.

[9] J.T Richardson, Magnetic Study of Cobalt Molybdenum Oxide Catalysts Ind. Eng. Chem. (fund.), 3,154 1964.

[10] J. H. Ashley and P. C. H. Mitchell, Cobalt-molybdenumalumina hydrodesulphurisation catalysts. Part I. A spectroscopic and magnetic study of the fresh, catalyst and model compounds, J. chem. Soc., (A), 2821-2827, 1968.

[11] J. M. J. G. Lipsch and G.C.Aschuit, The CoO-MoO3-A12O3 Catalyst. III. CatalystProperties, J. catal., 15, 179,1969.

[12] S. Greenwald, J. Pickard, and F. H. Grannis, Cation Distribution and $\mathrm{g}$ Factors of Certain Spinels Containing $\mathrm{Ni}++, \mathrm{Mn}++, \mathrm{Co}++, \mathrm{Al}+++, \mathrm{Ga}+++$, and $\mathrm{Fe}+++$, J. Chem.
Phys., 22, 1597,1954

[13] J. M. J. G. Lipsch and G. C. A. Schuit, The CoO-MoO3-A12O3 catalyst: II. The structure of the catalyst, J. Catal., 15,174, 1969.

[14] Hamid A. Al-Megren, ,Hydrodesulfurization of Thiophene Over BimetallicI Ni-Mo Sulfide Catalysts Prepared By Different Methods. The Arabian Journal for Science and Engineering, Volume 34, (1A), , pp 55, Jan. 2009

[15] U. T.Kubota, Y. Araki, K. Ishida, Y. Okamoto, The effect of boron addition on the hydrodesulfurization activity of MoS2/Al2O3 and Co-MoS2/Al2O3 catalysts, J. Catal., 227, 523-529, 2004

[16] U. T. Kubota, I. Hiromitsu, Y. Okamoto, Effect of boron addition on the surface structure of $\mathrm{Co}-\mathrm{Mo} / \mathrm{Al} 2 \mathrm{O} 3$ catalysts $\mathrm{J}$. Catal., 247, 78-85, 2007.

[17] A.M. Veneziaa1, F. Raimondib, V. La Parolab, G. Deganelloab, Influence of Sodium on the Structure and HDS Activity of Co-Mo Catalysts Supported ON Silica and Alumino silicate, J. catalysis,vol.194, (2) , 393-400, Sep.2000.

[18] J.M.Ammus, Ph.D. Thesis, Catalyst Deactivation during the Hydrotreatment of Thassos Heavy Oil Residue NTUA, Athens, 1985.

[19] J. Ammus , G.P. Androutsopoulos, A. H. Tsetsekou, An investigation of the deactivation Phenomena Associated with the Use of Commercial HDS Catalysts, Ind. Eng. Chem. Res ,26, 312-1323, 1987.

[20] V. H. J. De Beer et. al., The CoO-MoO3-A12O3 catalyst. IV. Pulse and continuous flow experiments and catalyst promotion by cobalt, nickel, zinc, and manganese, J. Catal. 27,357, 1972.

[21] L.Coulier, V. H. J. De Beer, J. A. R. Van Veen and J. W. Niemantsverdriet, Topics in Catalysis, 13, 99, 2000.

[22] L.Coulier, V. H. J. De Beer, J.A.R. Van Veen and J.W. Niemantsverdriet, Topics in Catalysis, 197, 26, 2001.

[23] V.H.J. de Beer, et. Al., The CoO-MoO3- $\gamma-\mathrm{Al} 2 \mathrm{O} 3$ catalyst: V. Sulfide catalysts promoted by cobalt, nickel, and zinc, J. Catalysis, 35, 297,1974 